\title{
Nachweis gentechnischer Veränderungen in Mais mittels PCR
}

\author{
Von B. Ehlers, E. Strauch, M. Goltz, D. Kubsch, H. Wagner, H. Maidhof, J. Bendiek, B. Appel \\ und H.-J. Buhk
}

\section{Zusammenfassung}

Ein PCR-Nachweis für gentechnisch veränderten Mais "Event 176 « der Fa. Ciba-Geigy wurde etabliert. Der Mais enthält Gene, die Selbstschutz gegen den Maiszünsler (DeltaEndotoxin-Gen aus Bacillus thuringiensis) und Toleranz gegen das Herbizid Basta (Phosphinothricin-Resistenz-Gen aus Streptomyces bygroscopicus) vermitteln. Zudem enthält der Mais ein Ampicillin-Resistenz-Gen. Für die Amplifikation von Bereichen aus allen drei Genen wurden PCR-Primer entworfen. Mit Hilfe dieser Primer und mit »Event 176«Mais-DNA als Template konnten die entsprechenden Genbereiche in der PCR amplifiziert werden. Die PCR-Produkte wurden sequenziert, um ihre Identität zu bestätigen. Mit Hilfe der Delta-Endotoxin-PCR wurden, auch in Gegenwart von $10^{4}$ fachem Überschuß nicht gentechnisch veränderter Mais-DNA, fünf haploide Genome der »Event 176«-DNA nachgewiesen.

\section{Summary \\ Identification of genetically modified maize by PCR}

A PCR-test for the genetically modified maize "Event 176 " of Ciba-Geigy was established. The maize contains genes conferring resistance to the European corn borer (delta-endotoxin gene from Bacillus thuringiensis) and tolerance to the herbicide Basta (phosphinothricin resistance gene from Streptomyces bygroscopicus). The maize contains also an ampicillin resistance gene. Primers were designed and using »Event $176 \ll-$ maize-DNA as template internal regions of the three genes were amplified with PCR. The PCR products were sequenced to confirm their identity. Using the deltaendotoxin primers in PCR down to 5 haploid genomes of »Event 176 «-DNA could be detected, even in the presence of a $10^{4}$ fold excess of DNA from non-modified maize.
Resistenz gegen Schädlinge ist eine der Eigenschaften, die mit Hilfe gezielter genetischer Veränderungen in Nutzpflanzen eingebracht werden. Dem hier untersuchten Mais ("Event 176«) wurde von der Firma Ciba-Geigy mit dem cryIA(b)-Gen aus Bacillus thuringiensis ein Delta-Endotoxin-Gen übertragen, das einen Selbstschutz gegen den Maiszünsler (Ostrinia nubilalis) vermittelt. $\mathrm{Zu}$ Selektionszwecken wurde, zusammen mit dem cryIA(b)-Gen, ein Gen (bar) eingebracht, dessen Expression Toleranz gegen das Herbizid Basta vermittelt. Weiter wurde das $\beta$-LactamaseGen $\left(a m p^{\mathrm{R}}\right)$ eingeführt, das aus dem Plasmid stammt, in dem die gentechnische Konstruktion zunächst in Escherichia coli erfolgte. Es kann in Bakterien Ampicillinresistenz bewirken. Das Plasmid wurde zur Transformation des Mais benutzt.

Dieser Mais wurde 1996 in den USA bereits auf ca. $0,5 \%$ der Maisanbaufläche angebaut. Die Genehmigung zum uneingeschränkten Inverkehrbringen dieses Mais in der Europäischen Union wurde von der Firma Ciba-Geigy gemäß Richtlinie 90/220/EWG in Frankreich beantragt und nach Entscheidung durch die EU-Kommission von der zuständigen französischen Behörde im Februar 1997 ausgesprochen.

Ziel einer Arbeitsgruppe im Fachbereich Genetik, Gentechnik des Robert Koch-Institutes war es, kurzfristig ein PCR-Verfahren zu etablieren, das einen spezifischen und hinreichend sensitiven Nachweis der gentechnischen Veränderungen erlaubt und es den für den Vollzug des Gentechnikgesetzes zuständigen Behörden ermöglicht, Überwachungsaufgaben durchzuführen.

\section{Methode}

Es wurden analysenreine, für die Molekularbiologie bestimmte Chemikalien (inklusive $\mathrm{H}_{2} \mathrm{O}$ ) und weitestgehend Einweg-Materialien verwendet. Glasgefäße und Mörser wurden autoklaviert. Sie sollten zudem durch Abflammen oder chemisch-physikalische Behandlung von DNA-Spuren befreit werden.

Die Aufarbeitung von gentechnisch verändertem Mais und nicht verändertem Mais erfolgte mit verschiedenen Geräten sowie zeitlich und räumlich getrennt, um Kreuzkontamination der Untersuchungsmaterialien zu verhin- dern. In einem jeweils anderen räumlichen Bereich erfolgten das Ansetzen der PCR-Reaktionen sowie die Analysen der Amplifikate (Gelelektrophorese, Sequenzierung), um falsch-positive PCRSignale durch Kontamination zu vermeiden.

\section{DNA-Präparation}

Die DNA-Präparation wurde durchgeführt in Anlehnung an: Dellaporta, S., "Plant DNA Miniprep and Microprep«, aus: Freeling, M., und Valbot, V. (Hrsg.): The Maize Handbook; Springer Verlag, 1994, S. 521.

Fünf bis sieben Maiskörner (ca. 1,7 g) wurden grob zerkleinert und nach $\mathrm{Zu}$ gabe von $1 \mathrm{~g}$ Seesand und flüssigem Stickstoff im Mörser pulverisiert. Das Maismehl-Sandgemisch wurde mit $7 \mathrm{ml}$ Extraktionspuffer $(50 \mathrm{mM}$ Tris- $\mathrm{HCl}$, $20 \mathrm{mM}$ EDTA, $100 \mathrm{mM} \mathrm{NaCl}, 1 \%$ SDS, $10 \mathrm{mM} \quad \beta$-Mercaptoethanol, $\mathrm{pH} 8,0$; $65^{\circ} \mathrm{C}$ ) versetzt, $10 \mathrm{Min}$. bei $65^{\circ} \mathrm{C}$ inkubiert, dann mit 2,5 ml 5M-KaliumacetatLösung gemischt, $30 \mathrm{Min}$. im Eisbad inkubiert und $10 \mathrm{Min}$. bei $10000 \mathrm{~g}$ zentrifugiert. Der Überstand (ca. $7 \mathrm{ml}$ ) wurde mit $0,7 \mathrm{Vol}$. Isopropanol gemischt und 
10 Min. bei $10000 \mathrm{~g}$ zentrifugiert, das Sediment mit $80 \%$ kaltem Ethanol gewaschen, getrocknet und aufgenommen in $1 \mathrm{ml}$ Puffer $(10 \mathrm{mM}$ Tris- $\mathrm{HCl} \mathrm{pH} 8$, $5 \mathrm{mM}$ EDTA ; $60^{\circ} \mathrm{C}$ ). Nach $10 \mathrm{Min}$. im Eisbad wurde $10 \mathrm{Min}$. bei $10000 \mathrm{~g}$ zentrifugiert und der Überstand mit $40 \mu \mathrm{g} / \mathrm{ml}$ RNAse A (DNAse-frei) für $1 \mathrm{~h}$ bei $37^{\circ} \mathrm{C}$ inkubiert. Nach jeweils einmaliger Extraktion mit 1 Vol. Phenol-Chloroform-Isoamylalkohol (25:24:1) und 1 Vol. Chloroform-Isoamylalkohol (24:1) wurde der wässrige Überstand mit $0,7 \mathrm{ml} 3 \mathrm{M}-\mathrm{Na}$ triumacetat-Lösung $\mathrm{pH}$ 5,2 versetzt und mit TE-Puffer auf $7 \mathrm{ml}$ aufgefüllt. Nach erneuter DNA-Fällung (s. o.) wurde das gewaschene und getrocknete Pellet in 250-500 $\mu$ l TE-Puffer (10 mM Tris- $\mathrm{HCl}$ pH 8, 1 mM EDTA) aufgenommen. Die DNA-Konzentration wurde dann fluorometrisch bestimmt und die Reinheit der DNA mittels Agarose-Gel-Elektrophorese und Messung des UV-Spektrums überprüft.

Aus $1 \mathrm{~g}$ trockener Maiskörner wurden 40-60 $\mu \mathrm{g}$ DNA in Fragmenten von 10 bis $>50 \mathrm{~kb}$ Länge isoliert.

DNA, die ohne Extraktion mit organischen Lösungsmitteln isoliert wurde, ergab in der PCR vergleichbare Resultate.

\section{PCR-Primer}

Folgende Primer wurden entworfen (Tab. 1):

Delta-Endoroxin-Gen aus Bacillus thuringiensis (cryIA(b)-Gen: crystal protein gene): Die Sequenz des modifizierten Gens ist nicht veröffentlicht und wurde von der Firma Ciba-Geigy zur Verfügung gestellt. Es wurde ein
Primerpaar aus dem Bereich des Gens ausgewählt, der für das aktive, nach Trypsin-Verdau erhaltene insektizide Protein kodiert (Primer: cryIA[b]).

Phosphinothricin-Resistenzgen aus Streptomyces hygroscopicus (bar-Gen): Von Ciba-Geigy wurde die Sequenz des verwendeten bar-Gens zur Verfügung gestellt. (a) Es wurde ein Primer-Paar ermittelt, das einen Teil der kodierenden Sequenz des bar-Genes amplifiziert (Primer: bar). (b) Die Expression des bar-Gens im gentechnisch veränderten Mais erfolgt vom 35S-Promotor des Cauliflower Mosaic Virus. Mittels publizierter Sequenzen (Genbank-Nr. A18053) wurde zusätzlich ein Primerpaar ausgewählt, das den Bereich des 35S-Promotors vor dem mRNA-Start sowie den $\mathrm{N}$-terminalen Bereich des bar-Genes amplifiziert (Primer: 35Sbar).

Ampicillin-Resistenzgen aus dem Plasmid pUC19: Es wurde ein Primerpaar gewählt, das die Sequenz der kodierenden Region (861 bp) fast vollständig amplifiziert (828 bp); der Sense-Primer beginnt 12 bp nach dem 5'-Ende der kodierenden Region, der Antisense-Primer endet $21 \mathrm{bp}$ vor dem $3^{\prime}$-Ende der kodierenden Region (Primer: $a m p^{R}$ ).

Invertase-Gen aus Mais: Für Kontrollzwecke wurde das ivr1-Gen verwender, das für eine Invertase kodiert (Genbank-Nr. U16123). Die amplifizierte Sequenz ist Teil des Exon 3 (Primer: ivr1).

Alle Primer wurden mit Hilfe des Programmes "Primer Premier Version 4.0 (Fa. Premier Biosoft International, Palo Alto; USA) ausgewählt und von Fa. Pharmacia bezogen.

Tabelle 1: Primersequenzen für die PCR

\begin{tabular}{|c|c|c|c|c|c|c|c|c|c|c|}
\hline Gen & $\begin{array}{l}\text { Primer } \\
\text { (sense/ }\end{array}$ & $\begin{array}{l}\text { sequen } \\
\text { antisen }\end{array}$ & $\begin{array}{l}z 5^{\prime} \rightarrow 3^{\prime} \\
\text { se) }\end{array}$ & & & & & & & $\begin{array}{l}\text { Länge des PCR- } \\
\text { Produktes (bp) }\end{array}$ \\
\hline ivr1 & $\begin{array}{l}\text { CCG } \\
\text { GGA }\end{array}$ & $\begin{array}{l}\text { CTG } \\
\text { GCC }\end{array}$ & $\begin{array}{l}\text { TAT } \\
\text { CGT }\end{array}$ & $\begin{array}{l}\text { CAC } \\
\text { GTA }\end{array}$ & $\begin{array}{l}\text { AAG } \\
\text { GAG }\end{array}$ & $\begin{array}{l}\text { GGC } \\
\text { CAT }\end{array}$ & $\begin{array}{l}\text { TGG } \\
\text { GAC }\end{array}$ & $\begin{array}{l}\text { TAC } \\
\text { GAT }\end{array}$ & C & $226^{1}$ \\
\hline ryIA(b) & $\begin{array}{l}\text { ACC } \\
\text { TGG }\end{array}$ & $\begin{array}{l}\text { ATC } \\
\text { GGA }\end{array}$ & $\begin{array}{l}\mathrm{AAC} \\
\mathrm{ACA}\end{array}$ & $\begin{array}{l}\text { AGC } \\
\text { GGC }\end{array}$ & $\begin{array}{l}\text { CGC } \\
\text { TCA }\end{array}$ & $\begin{array}{l}\text { TAC } \\
\text { CGA }\end{array}$ & $\begin{array}{l}\text { AAC } \\
\text { TGT }\end{array}$ & $\begin{array}{l}\mathrm{GAC} \\
\mathrm{CCA}\end{array}$ & $\begin{array}{l}\mathrm{C} \\
\mathrm{G}\end{array}$ & $184^{1}$ \\
\hline bar & $\begin{array}{l}\text { GCA } \\
\text { AGC }\end{array}$ & $\begin{array}{l}\text { GGA } \\
\text { CCG }\end{array}$ & $\begin{array}{l}\text { ACC } \\
\text { ATG }\end{array}$ & $\begin{array}{l}\text { GCA } \\
\text { ACA }\end{array}$ & $\begin{array}{l}\text { GGA } \\
\text { GCG }\end{array}$ & $\begin{array}{l}\text { GTG } \\
\text { ACC }\end{array}$ & $\begin{array}{l}\mathrm{GA} \\
\mathrm{AC}\end{array}$ & & & $264^{1}$ \\
\hline $35 \mathrm{~S}-b a r$ & $\begin{array}{l}\text { GCA } \\
\text { TCC }\end{array}$ & $\begin{array}{l}\text { CAA } \\
\text { GTC }\end{array}$ & $\begin{array}{l}\text { TCC } \\
\text { CAC }\end{array}$ & $\begin{array}{l}\text { CAC } \\
\text { TCC }\end{array}$ & $\begin{array}{l}\text { TAT } \\
\text { TGC }\end{array}$ & $\begin{array}{l}\text { CCT } \\
\text { GGT }\end{array}$ & $\begin{array}{l}\text { TCG } \\
\text { TC }\end{array}$ & C & & ca. $365^{2}$ \\
\hline$a m p^{\mathrm{R}}$ & $\begin{array}{l}\text { CAT } \\
\text { GGC }\end{array}$ & $\begin{array}{l}\text { TTC } \\
\text { ACC }\end{array}$ & $\begin{array}{l}\text { CGT } \\
\text { TAT }\end{array}$ & $\begin{array}{l}\text { GTC } \\
\text { CTC }\end{array}$ & $\begin{array}{l}\text { GCC } \\
\text { AGC }\end{array}$ & $\begin{array}{l}\text { CTT } \\
\text { GAT }\end{array}$ & $\begin{array}{l}\text { ATT } \\
\text { CTG }\end{array}$ & $\begin{array}{l}\mathrm{CC} \\
\mathrm{TCT}\end{array}$ & A & $828^{1}$ \\
\hline
\end{tabular}

1 Länge des PCR-Produktes gemäß Sequenzdaten der Firma Ciba-Geigy.

2 Länge des PCR-Produktes gemäß publizierter Sequenzen (CaMV; bar) errechnet und durch Teilsequenzierung ermittelt.

\section{PCR}

Die DNA-Polymerase Amplitaq Gold ${ }^{\mathrm{TM}}$ (Fa. Perkin-Elmer) wurde verwendet, um das Ansetzen der PCR-Reaktionen bei Raumtemperatur zu ermöglichen und unspezifische Amplifikation vor dem Start der PCR zu verhindern. Die PCR-Reaktionen wurden wie folgt angesetzt:

1 Unit Amplitaq Gold ${ }^{\mathrm{TM}}$ DNA-Polymerase; $1 / 10$ Vol. 10xPuffer (Fa. Perkin Elmer); $200 \mu \mathrm{M}$ dNTP-Mix (Fa. Biometra); $1,25 \mathrm{mM} \mathrm{MgCl}_{2} ; 5 \%$ DimethylSulfoxid (DMSO, Fa. Sigma); je 0,5 $\mu \mathrm{M}$ Sense- und Antisense-Primer; $\mathrm{n} \mu \mathrm{l}$ DNA-Lösung; $\mathrm{H}_{2} \mathrm{O}$ (Fa. Fluka) ad $50 \mu \mathrm{l}$.

Die Ansätze wurden bis auf die Primer und die DNA-Lösung als Mastermix hergestellt. Zur Durchführung der PCR wurde ein »GeneAmp « PCR System 2400 Thermocycler ( $\mathrm{Fa}$. Perkin Elmer) mit folgenden Parametern eingesetzt:

- Aktivierung der Amplitaq GoldTM DNA-Polymerase und Denaturierung der DNA bei $95^{\circ} \mathrm{C} / 12 \mathrm{Min}$;

- 42 Zyklen mit $95^{\circ} \mathrm{C} / 30$ s (Denaturierung), $59^{\circ} \mathrm{C} / 30$ s für die Gene 35Sbar und $a m p^{\mathrm{R}}$ oder $64^{\circ} \mathrm{C} / 30 \mathrm{~s}$ für die Gene ivr1, cryIA(b) und bar (Annealing); $72^{\circ} \mathrm{C} / 30$ s (Elongation);

- abschließende Elongation bei $72^{\circ} \mathrm{C} / 10$ Min.; bis zur Analyse der PCR-Produkte $4^{\circ} \mathrm{C}$.

Gelelektrophoretische Auftrennung der PCR-Produkte erfolgte mit $2 \%$ Agarose in $2 \times$ TBE-Puffer (45 mM Tris-Bo-

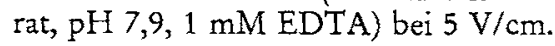

\section{Sequenzierung}

Zur Sequenzierung wurden die PCRAnsätze zunächst chromatografisch gereinigt, um PCR-Primer und Salze zu entfernen. Die Reinigung erfolgte über zentrifugierbare Chromatografiesäulen (»MicroSpin ${ }^{\mathrm{TM}}$ S-400 HR «, Fa. Pharmacia) nach Angaben des Herstellers.

Die Sequenzierung wurde als "CycleSequencing " mit Farbstoff-markierten Terminatoren durchgeführt. Zur Anwendung kam der $\gg$ Dye Terminator Cycle Sequencing Ready Reaction Kit " (Applied Biosystems/Perkin-Elmer). Das Protokoll des Herstellers wurde geringfügig modifiziert: Für jede Sequenzreaktion wurden $30 \mathrm{ng}$ PCR-Amplifikat, 4 pmol Primer und $6 \mathrm{ml}$ »Terminator Ready Reaction Mix« eingesetzt und 


\section{Originalien und Übersichtsarbeiten}

Wasser ad $20 \mathrm{ml}$ Endvolumen zugegeben.

Die Sequenzreaktion erfolgte in einem Thermocycler des Typs "GeneAmp PCR System 2400 « (Perkin-Elmer) unter folgenden Bedingungen: 2 Min. $30 \mathrm{~s} / 96^{\circ} \mathrm{C}$, anschließend 25 Zyklen mit $10 \mathrm{~s} / 96^{\circ} \mathrm{C}$ (Denaturierung), $5 \mathrm{~s} / 59^{\circ} \mathrm{C}$ bzw. $64^{\circ} \mathrm{C}$ (Annealing; Temperatur abhängig vom Primer) und 4 Min. $60^{\circ} \mathrm{C}$ (Elongation).

Nach Ende der Sequenzreaktion wurde die DNA nach Angaben des Herstellers gefällt, einmal gewaschen und getrocknet. Die Proben wurden anschließend auf automatischen DNA-Sequenzierungs-Automaten des Typs »ABI Prism $^{\text {TM }} 373 \mathrm{~A}$ und $310 \ll$ (Fa. Applied Biosystems/Perkin-Elmer) elektrophoretisch aufgetrennt, erfaßt und analysiert. Die Auswerung der Sequenzierungsergebnisse wurde mittels der Software "MacAutoAssembler ${ }^{\mathrm{TM}_{«}}$ (Fa. Applied Biosystems/Perkin-Elmer) vorgenommen.

\section{Ergebnisse}

Untersucht wurden

- Körner der gentechnisch veränderten Maislinie "Event 176« (Fa. CibaGeigy) mit den ins Chromosom integrierten Genen cryIA(b), bar und $a m p^{\mathrm{R}}$,

- Körner der nicht gentechnisch veränderten Ausgangsmaislinie CG00526 (Fa. Ciba-Geigy) sowie

- handelsüblicher Futtermais.

Mit DNA der Mais-Linie »Event 176 und den Primerpaaren cryIA(b), bar und $a m p^{\mathrm{R}}$ wurden Amplifikate erhalten, die die erwartete Größe (184 bp, $264 \mathrm{bp}$ und $828 \mathrm{bp}$ ) hatten (Abb. 1). Mit dem Primerpaar 35S-bar wurde ein Amplifikat von ca. 375 bp erhalten. Weder mit Futtermais-DNA (Abb. 1) noch mit DNA der Ausgangslinie CG00526 (ohne Abb.) konnten diese Sequenzen amplifiziert werden. Die Kontroll-PCR (Nachweis des Invertase-Gens) erzeugte mit allen drei Mais-DNAs Amplifikate der erwarteten Größe (226 bp) und gleicher Intensität. Sequenzierung der Amplifikate ergab in allen Fällen, daß die gesuchten Genabschnitte in der PCR amplifiziert wurden.

Die Gene cryIA(b), bar und $a m p^{\mathrm{R}}$ wurden damit in DNA der Mais-Linie "Event 176 «spezifisch nachgewiesen.

Die Sensitivität des oben gezeigten PCR-Nachweises wurde exemplarisch

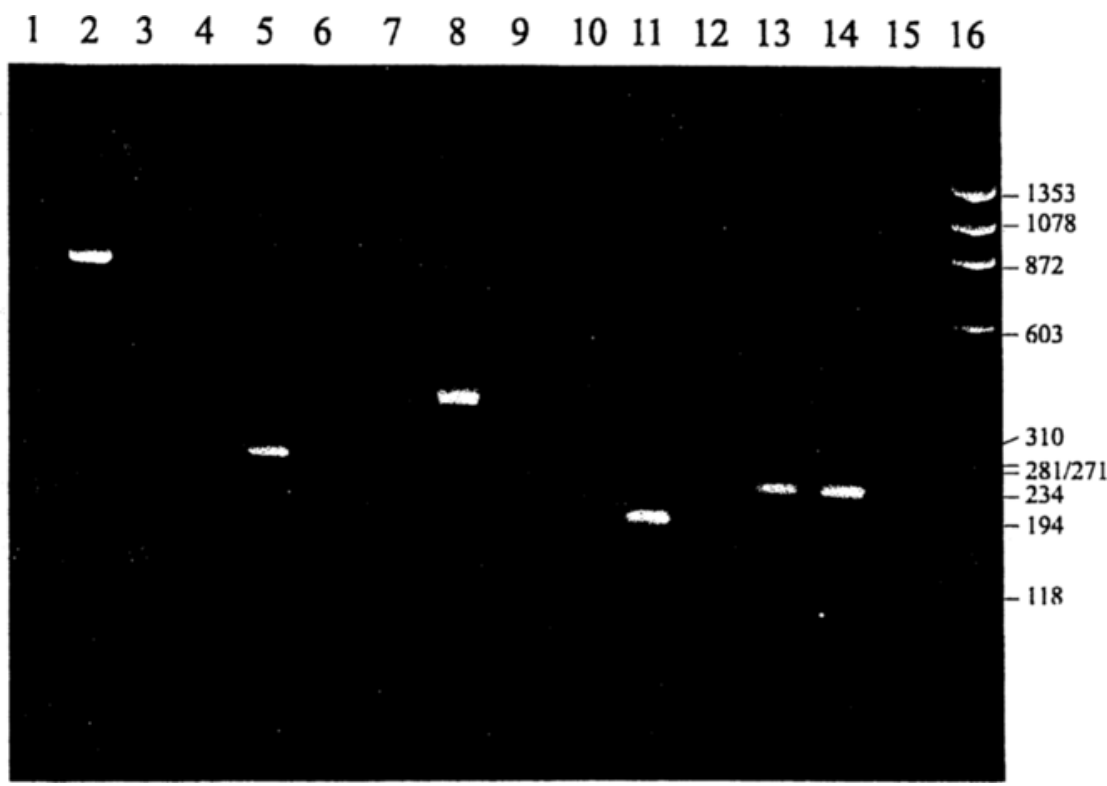

Abbildung 1: Nachweis des Delta-Endotoxin-Gens, des Phosphinothricin-Resistenz-Gens und des Ampicillin-Resistenz-Gens in gentechnisch verändertem Mais.

Als Template wurden $20 \mathrm{ng}$ DNA verwendet. Dies entspricht ca. $10^{4}$ haploiden Maisgenomen. Spur 1, 4, 7, 10, 13: PCR mit Kontrollmais (Futtermais)-DNA; Spur 2, 5, 8, 11, 14: PCR »Event 176«-Mais-DNA; Spur 3, 6, 9, 12, 15: PCR ohne DNA; Spur 1-3: Primer amp ${ }^{\text {R }}$; Spur 4-6 Primer bar; Spur 7-9: Primer 35S-bar; Spur 10-12: Primer cryIA(b); Spur 13-15: Primer ivr1; Spur 16: Molekulargewichtsstandard (Bakteriophage PhiX, HaeIII-Verdau; $450 \mathrm{ng}$ ).

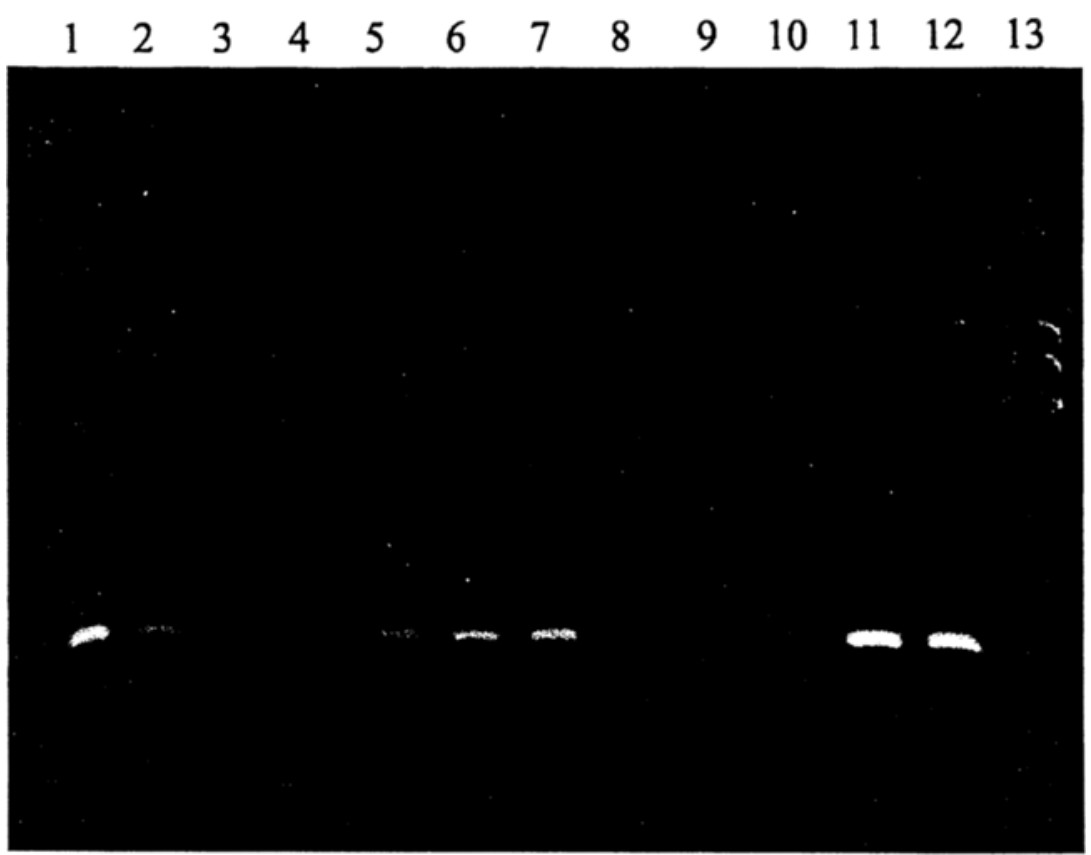

Abbildung 2: Nachweis des Delta-Endotoxin-Gens in DNA aus gentechnisch verändertem Mais (Mais-Linie $*$ Event $176 \%$ ), gemischt mit unterschiedlichen Mengen von DNA aus nicht gentechnisch verändertem Mais.

Als Template wurden 20 pg (Spur 1-4, 12) oder 10 pg (Spur 5-9, 11) „Event 176«-DNA verwendet. Dies entspricht ca. 10 bzw. 5 haploiden Maisgenomen. Amplifiziert wurde in Gegenwart von Kontroll-Mais-DNA: $20 \mathrm{ng}, 100 \mathrm{ng}, 200 \mathrm{ng}, 1000 \mathrm{ng}$ (Spur 1-4); $10 \mathrm{ng}, 50 \mathrm{ng}, 100 \mathrm{ng}, 500 \mathrm{ng}, 1000$ $\mathrm{ng}$ (Spur 5-9). (Spur 10: kein Template; Spur 11, 12: ohne Kontroll-Mais-DNA; Spur 13: Molekulargewichtsstandard (Bakteriophage PhiX, HaeIII-Verdau; $450 \mathrm{ng}$ ). 
mit dem Primerpaar cryIA(b) weiter untersucht. Ein deutliches und reproduzierbares PCR-Signal wurde noch mit 10 pg DNA erhalten (Abb. 2 Spur 11). Dies entspricht ca. fünf haploiden Maisgenomen.

Um abschätzen zu können, ob der Nachweis des cryIA(b)-Gens auch gelingt, wenn »Event 176 -Mais als Beimischung von unverändertem Mais vorliegt, wurde $»$ Event $176 \ll-$ Mais-DNA mit steigenden Mengen von DNA aus unverändertem Mais gemischt. Diese Mischungen wurden als Template in der PCR mit dem Primerpaar cryIA(b) verwendet. Abbildung 2 zeigt, daß der cryIA(b)-PCR-Nachweis noch an einer DNA-Mischung mit einem Mischungsverhältnis von 1:10 000 gelingt (Abb. 2, Spur 3 u. 7). Somit könnte der gentechnisch veränderte Mais auch dann noch identifiziert werden, wenn er lediglich als $0,01-\%$-Beimischung vorliegt.
Bei Mischungsverhältnissen von $1: 50000$ (Spur 4 u. 8) sowie 1:100000 (Spur 9) wurde kein PCR-Produkt mehr gefunden. Als Grund sind zu hohe absolute DNA-Konzentrationen $(0,5 \mu \mathrm{g}$ bzw. $1 \mu \mathrm{g})$ im PCR-Ansatz anzunehmen.

\section{Zusammenfassung und Diskussion}

Die Gene cryIA(b), bar und $a m p^{R}$ wurden in DNA der Mais-Linie "Event 176 spezifisch und mit hoher Sensitivität nachgewiesen. Die für das Gen cryIA(b) erzielte Sensitivität entspricht einem Nachweis des gentechnisch veränderten $»$ Event $176 \ll-$ Mais in $10^{4}$ fachem Überschuß von nicht gentechnisch verändertem Mais. An grünem Pflanzenmaterial wurde der PCRNachweis nicht durchgeführt. Es ist jedoch davon auszugehen, daß er hier ebenso einsetzbar ist.
Mit den verwendeten $a m p^{\mathrm{R}}$-Primern wurden 828 von 861 bp des $a m p^{R}-$ Gens amplifiziert. Es ist somit davon auszugehen, daß ein vollständiges $a m p^{R_{-}}-G_{-n}$ in der gentechnisch veränderten Pflanze erhalten geblieben ist.

Die Überprüfung der Identität der PCR-Produkte wurde durch Bestimmung von Teilsequenzen vorgenommen, um eindeutige Resultate zu erhalten. Geeignete, technisch weniger aufwendige Alternativen sind Restriktionsverdau von PCR-Produkten mit nachfolgender gelelektrophoretischer Analyse der DNA-Fragmente oder Southern Blot-Hybridisierung mittels geigneter Sonden.

Anschrift der Verfasser:

Dr. B. Ehlers, Dr. E. Strauch, Dr. M. Goltz, D. Kubsch, Dr. H. Wagner, Dr. H. Maidhof, Dr. J Bendiek, Prof. Dr. B. Appel und Dr. H.-J. Buhk, Fachbereich Genetik, Gentechnik, Robert KochInstitut, Postfach 650280,13302 Berlin 